\title{
A Gratificação de Estímulo à Docência (GED) NA UNIVERSIDAdE FEDERAL dE UBERLÂNDIA-MG: UMA ANÁLISE DE PESQUISA NO CAMPO DO ENSINO SUPERIOR*
}

Mara Rúbia Alves Marques**

\section{RESUMO}

Este texto constitui análise da pesquisa Políticas de Avaliação Docente no Ensino Superior, de Vânia Amaral da Rocha. Produzido para subsidiar minha participação como membro titular da banca de defesa da dissertação correspondente, o objetivo do texto foi tratar do processo de pesquisa de Vânia Rocha, de modo a contribuir para uma auto-reflexão sobre meu próprio trabalho de orientação no Programa de Pós-Graduação em Educação da UFU, como para a auto-reflexão da autora sobre sua investigação no campo das políticas públicas para o ensino superior. Para tanto, com base no referencial teórico de Isaura Belloni, Heitor de Magalhães e Luzia Sousa, trato, respectivamente, da temática, da relevância e metodologia, dos referenciais de análise e dos resultados da referida pesquisa.

Palavras-Chave: pesquisa em educação; políticas públicas; educação superior; avaliação.

Aqui se expressa o paradoxo da GED, pois da mesma forma que flexibiliza a organização dos processos de trabalho nas IFES, estabelece critérios e normas de padronização do perfil profissional docente.

VÂNIA RochA

\footnotetext{
* Artigo recebido em 5/2/2006 e aprovado em 29/4/2006.

** Professora doutora do curso de Pedagogia e do Programa de Pós-Graduação em Educação da Faculdade de Educação/FACED da Universidade Federal de Uberlândia/UFU. E-mail: mara@ufu.br.
} 


\section{DA TEMÁTICA}

A pesquisa refere-se à dissertação de mestrado de Vânia Rocha, defendida no Programa de Pós-Graduação em Educação (PPGE), da Faculdade de Educação da Universidade Federal de Uberlândia (UFU), em abril de 2005. Ela é vinculada ao Núcleo de Políticas Públicas e Gestão em Educação, da linha de pesquisa homônima do curso de mestrado em educação, o qual tem como eixo temático central Estado, Trabalho e Educação, que se desdobra em quatro subeixos, a saber: Novas Configurações do Mundo do Trabalho, Novas Configurações do Estado e Qualificação Profissional, Reformas Educacionais e Impactos nas Instituições Educativas.

A meu ver, no referido núcleo, o trabalho de Rocha (2005) está ligado aos subeixos Novas Configurações do Estado e Qualificação Profissional, e Reforma Educacional, sobretudo no que diz respeito às alterações na gestão estatal de sistemas educacionais, uma vez que a questão do ensino superior é analisada no quadro amplo de mudanças administrativas e educacionais ocorridas no Brasil nos anos de 1990.

Tratando-se da problemática da avaliação, consideramos, para fins de análise, a categorização de Isaura Belloni, Heitor de Magalhães e Luzia Sousa (2001), ${ }^{1}$ que usam as expressões "avaliação institucional" e "avaliação de políticas públicas" de modo integrado, "porque elas fazem parte de um mesmo tipo de avaliação, distinta do campo da avaliação [educacional] de aprendizagem e desempenho, seja do ponto de vista do objeto da avaliação, seja do ponto de vista metodológico" (p. 10); embora também distingam ambas, "avaliação institucional" e "avaliação de políticas públicas", no que diz respeito ao objeto da avaliação.

Assim, do ponto de vista de uma temática específica, a pesquisa de Rocha (2005) articula "avaliação institucional" e "avaliação de políticas públicas", por meio da análise de uma política específica de avaliação profissional dos docentes funcionários-públicos do sistema brasileiro de ensino superior, no contexto propriamente empírico da UFU - a gratificação de estímulo à docência (GED). ${ }^{2}$

O ponto central da investigação é, pois, apreender e avaliar o significado da GED na UFU por meio de alguns questionamentos: tais como: Quais os parâmetros que nortearam a proposta da GED pelo MEC? Qual foi a reação do movimento docente? Quais as 
principais críticas e sugestões dos docentes em relação a GED? (Rocha, 2005, p. 5).

Embora a autora admita, com base em uma vivência atenta no âmbito do quadro funcional da Universidade Federal de Uberlândia, bem como em pesquisa desenvolvida anteriormente, ${ }^{3}$ seu despertado interesse "para uma análise mais crítica das mudanças ocorridas na gestão e organização da instituição, as quais se deram com maior intensidade no segundo mandato de governo de FHC (1998-2002)" (Rосна, 2005, p. 2), situo a atual pesquisa mais apropriadamente no campo da "avaliação de uma política pública", ${ }^{4}$ em detrimento da ênfase ao campo da "avaliação institucional".

Para efeito de distinção, segundo Belloni, Magalhães e Sousa (2001), a diferença entre ambas - avaliação de uma política pública e avaliação institucional - diz respeito ao objeto de investigação, sendo que

na avaliação institucional busca-se tratar, de modo global e sistemático, uma instituição. São analisadas as políticas institucionais, bem como os programas e projetos desenvolvidos para a implementação das políticas institucionais; é examinado o atendimento aos objetivos de cada uma das políticas e projetos, assim como a consecução dos objetivos e finalidades da instituição, isto é, sua "missão institucional". (Belloni; MagalHães; Sousa, 2001, p. 10).

Considera-se que, no primeiro campo de investigação, avaliação de uma política pública,

as instituições responsáveis pela formulação ou implementação da política não são parte do objeto da avaliação. Nesse caso, são examinadas apenas as políticas - entendidas como o conjunto de orientações e ações de um governo com vistas ao alcance de determinados objetivos - e os seus resultados e consequiências (Belloni; Magalhães; Sousa, 2001, p. 10).

\section{DA RELEVÂNCIA E METODOLOGIA}

Depreende-se, em todo caso, a justificativa e a relevância do esforço da investigação analisada, supondo que: 
Uma instituição ou uma política pública tem finalidades e desempenha papéis sempre mais amplos e significativos do que aqueles expressos nos seus objetivos explícitos, principalmente em decorrência de sua introdução com outras políticas e instituições sociais. Neste sentido, é necessário desenvolver esforços conceituais e experiências com vistas à elaboração de metodologias que possibilitem avaliação da eficiência, da eficácia e da efetividade social de políticas públicas ou de instituições. (Belloni; MagalHães; Sousa, 2001, p. 10-11).

A relevância da pesquisa se expressa, ainda, a partir da seguinte constatação:

A avaliação institucional e de políticas públicas é uma área ainda incipiente do ponto de vista conceitual e metodológico. Existem poucas experiências e tradição de avaliação sistemática de desempenho e de resultados, seja do funcionamento de instituições, seja da implementação de políticas públicas. (Belloni; MagalHães; Sousa, 2001, p. 9)

Do ponto de vista metodológico, ao visar "apreender o significado da implantação da gratificação de estímulo à docência (GED) na Universidade Federal de Uberlândia (UFU), a pesquisa supera limites metodológicos recorrentes, já que, segundo os autores supracitados, "as metodologias adotadas, em geral, concentram-se na aferição de impacto quantitativo" (Belloni; Magalhães; Sousa, 2001, p. 9). E, neste caso, "a avaliação institucional e de políticas públicas torna-se mais relevante quando pode oferecer informações não apenas sobre impacto, mas sobre resultados ou conseqüências mais amplas e difusas das ações desenvolvidas" (Belloni; Magalhães; Sousa, 2001, p.9).

Logo na Introdução de seu trabalho, para não cair na armadilha do mero impacto quantitativo, Vânia Rocha (2005) mune-se do referencial qualitativo ao afirmar que "o pesquisador qualitativo preocupa-se com o processo e não simplesmente com o resultado do produto." (BogDAN e BiKLEN, 1994 apud Rocha, 2005, p. 6); e que o acompanhamento do processo de ocorrência do fenômeno pesquisado implica "descobrir suas relações e avançar no conhecimento de seus aspectos evolutivos, tratando de identificar as forças decisivas responsáveis por seus desenrolar característico" (Triviños, 1987, apud Rocha, 2005, p. 6). 
DOS REFERENCIAIS DE ANÁLISE

Ainda conforme Isaura Belloni, Heitor de Magalhães e Luzia Sousa (2001, p. 29):

a avaliação de uma política pública deve considerar alguns parâmetros referenciais de análise: política como um dos instrumentos de ação do Estado, conceitos e perspectivas político-filosóficas relativas á questão objeto da política, e a política específica tal como é formulada e implementada.

Embora a pesquisa de Vânia Rocha (2005) não trate da educação profissional propriamente dita, como é o caso do trabalho dos autores supracitados, meu suposto é de que políticas de qualificação profissional, de formação de profissionais da educação - docentes e dirigentes/gestores - bem como de políticas públicas como a GED, no caso, representam processos pedagógicos de formação de uma subjetividade profissional.

Todas se equivalem em pelo menos dois aspectos, ou seja, pelo sentido que imprimem a uma determinada conformação do trabalho docente e pela possibilidade de serem analisadas sob o crivo dos mesmos "conjuntos de parâmetros conceituais".

Um primeiro conjunto de referências - "Globalização, reestruturação produtiva e educação profissional" (BELLONI; MAGALHãES; SousA, 2001, p. 29) - se expressa no fato de que a análise "remete ao exame das influências dominantes no mundo do trabalho, em especial aqueles decorrentes da reestruturação produtiva e da globalização, além daquelas oriundas da história e da cultura individual e coletiva" (BELLONI; MAGALHÃES; Sousa, 2001, p. 30).

Um segundo conjunto de referências - "Política pública como objeto de avaliação" - está em considerar que:

Uma política pública desempenha distintos papéis, dependendo do setor/grupo social ao qual se destina e do tipo de relação que estabelece com as demais políticas (Belloni; Magalhães; Sousa, 2001, p.33).

Neste conjunto de referências, além dos traços já apontados nos resultados da avaliação da avaliação da GED, a pesquisa de Vânia Rocha indica que a GED é parte de uma política pública setorial do Ministério 
da Educação e Cultura (MEC) para o ensino superior, impingida diretamente aos trabalhadores da educação das universidades públicas. Indicando, também, a característica de ser uma política pública "congruente com uma política econômica básica (que é o fio condutor e reflete as prioridades de ação de um determinado governo) e está ligada a ela" (Belloni; Magalhães; Sousa, 2001, p. 33). ${ }^{5}$

Um terceiro conjunto de referências diz respeito, por fim, aos parâmetros propriamente empíricos da pesquisa, no sentido de "analisar o processo e o significado da GED na UFU" (Rocha, 2005, p. 4), o que remete à forma peculiar de gestão institucional, bem como ao comportamento individual e coletivo dos docentes perante e durante o processo de implementação da referida política.

Daí a pertinência da justificativa do uso da técnica da análise de conteúdo de um corpus significativo de documentos institucionais, a adequação é mais que coerente (VALA, 1986; BAUER, 2000 apud Rocha, 2005, p. 7-8).

Neste aspecto, entretanto, considerando o uso da análise de conteúdo na área da educação (OLiveira et al., 2003), com seus respectivos procedimentos de interpretação e análise de dados, e considerando, especificamente, "as etapas de execução da análise de conteúdo" (OliverRA et al., 2003, p. 16-20), ${ }^{6}$ no esforço analítico de Rocha identifiquei como que uma ausência da "definição de categorias", sobretudo de categorias a posteriori (OliveIRA et al., 2003, p. 19). Vejamos:

A terceira etapa da pesquisa consiste na definição das categorias. Esta etapa é muito importante, pois a qualidade de uma análise de conteúdo possui uma dependência como [sic] o seu sistema de categoriais. A categorização gera classe que reúnem um grupo de elementos da unidade de registro. As classes são compiladas a partir da correspondência entre a significação, a lógica do senso comum e a orientação teórica do pesquisador. Portanto, os critérios para a categorização podem ser semânticos; sintáticos; léxico ou expressivos. Ainda, Bardin indica a possibilidade de uma categorização com categorias a priori, sugeridas pelo referencial teórico e com categorias a posteriori, elaboradas após a análise do material. (Oliveira et al, 2003, p.19)

No entanto, como argumentei então, tal ausência - bastante justificável perante as atuais condições de elaboração de uma dissertação de mestrado - não compromete os resultados da pesquisa em questão. 


\section{Dos RESULTADOS}

Pautada em "categorias a priori", é justamente a ampla pesquisa documental que permite a autora apreender "uma dimensão que a GED foi assumindo na organização do ensino superior dessas IFES, especialmente no que se refere a uma conformação do trabalho docente ao modelo de desenvolvimento institucional preconizado nas políticas educacionais dos anos de 1990" (RосHA, 2005, p. 112).

Isso significa afirmar que, se por um lado, a GED favoreceu a um processo de diferenciação salarial nas instituições, por outro lado, em boa medida, contribuiu, também, para uma crescente padronização do trabalho entre as IFES e no interior de cada Instituição. Assim como no processo de reconfiguração do mundo do trabalho, marcado por uma flexibilização na organização dos processos de trabalho acompanhada de uma padronização flexível da produção, também no caso da educação superior [...] presenciamos a um processo de padronização flexível de trabalho científico e acadêmico. (RоcнA, 2005, p. 112-113)

Faz sentido, portanto, a título de considerações finais, as quais bem podem corresponder aos pressupostos iniciais da pesquisa, as afirmações de caráter abrangente - e nem por isso menos certeiras - de que, quanto ao sistema institucional, "a legislação educacional nacional passou por várias alterações para incorporar a aplicabilidade do modelo de educação superior diversificado e flexível" (Rосна, 2005, p. 124); e de que, quanto ao sistema institucional-profissional, estabeleceu-se com a instituição da GED uma "padronização flexível do trabalho intelectual na educação superior” (RocHA, 2005, p. 126).

De modo que:

a GED representou a constituição de um novo padrão profissional para as IFES, baseado em critérios de produtividade que favorecem a quebra da isonomia e da paridade salarial entre os docentes em exercício, aposentados e pensionistas. Conseqüentemente, propiciou $\mathrm{o}$ incentivo à competitividade, ao individualismo e o processo de "mercantilização" da educação pública. (RосHA, 2005, p. 124)

Com efeito, a padronização flexível [...] corrobora com o processo mais amplo de flexibilização da organização do trabalho e da produção para se obter maior produtividade em tempos de acumulação flexível. 
Da mesma forma, confirma a proposta do governo na nova reforma da educação superior: tornar as universidades mais operacionais para atender o modelo excludente de desenvolvimento econômico imposto pelo ideário neoliberal no mundo globalizado. (RochA, 2005, p. 126)

Neste contexto híbrido de "flexibilidade, competitividade e avaliação", a pesquisa é reveladora de paradoxos ou contradições interessantes, principalmente no capítulo IV que "visa apreender, a partir dos documentos internos da UFU, como os parâmetros e o sentido da avaliação foram debatidos no processo de implementação da GED" (Rосна, 2005, p. 83).

Um primeiro paradoxo se estabelece na forma centralizada, impositiva, burocrática e apressada de instituição do novo mecanismo (Rocha, 2005, p. 95-113) e na concomitante facilidade com que o "espírito" da GED foi incorporado ao cotidiano institucional e profissional, em termos de ajustes e adequação ao sistema, de aprimoramento de sua eficiência e eficácia, e, ainda de relações competitivas entre os docentes (RochA, 2005, p. 96-121).

Ao estabelecer um período exíguo para adequação dos procedimentos de pontuação e avaliação do desempenho docente, com risco dos docentes não receberem o pagamento da gratificação, as IFES foram levadas a apressarem o enquadramento de suas normas às diretrizes definidas pela CNAO-GED, instituída pelo MEC. (RochA, 2005, p. 84) ${ }^{7}$

Por sua vez, essa semelhança de resultados [entre os três Centros] indica, também, o quanto as IFES se ajustaram ao modelo de avaliação de caráter produtivista, homogeneizador instituído, apesar da diversidade da natureza e especificidades de atividades de cada campo de saber. [...] mesmo nos recursos encaminhados não se observam questionamentos mais consistentes sobre essa lógica. (RосHA, 2005, p. 96)

o esforço empreendido pelo corpo docente da instituição a partir da implantação da GED na UFU foi, predominantemente, no sentido de inserir as diversas atividades que desenvolviam no formulário a ser utilizado no processo avaliativo para concessão da GED. [...] Isso demonstra, ainda, que os docentes começaram a internalizar no "espírito" da GED, a medida em que reconheciam que seria preciso provar que estavam realmente exercendo suas atividades dentro dos critérios estabelecidos para se ter direito à gratificação. (RocHA, 2005, p. 104) 
Um segundo paradoxo se estabelece no argumento da necessidade de se cumprir a Lei de Diretrizes e Base da Educação Nacional e na preocupação das IFES em sofrer "ingerência" do MEC, comprometendo o exercício da autonomia da universidade (RochA, 2005, p. 114-118).

Temos, assim, a síntese dos paradoxos das reformas educacionais contemporâneas brasileiras que a presente pesquisa expressa: um conjunto de estratégias oficiais centralizadas e padronizadas para descentralizar/ diversificar institucionalmente e desagregar política e profissionalmente, mediante desempenhos performáticos competitivos controlados por processos e/ou programas de avaliação, tanto das instituições como das pessoas-profissionais a elas vinculadas.

A pesquisa de Rocha tende a confirmar alguns supostos com os quais venho trabalhando há algum tempo (MARQUES, 2000, 2000a), relativos aos mecanismos de desprofissionalização e despolitização dos docentes postos em ação pelas atuais políticas educacionais, cuja gestão sobre a autonomia das instituições públicas tendem a alterar o estatuto dos profissionais funcionarizados. Como abordagem sócio-histórica e sociológica, a ênfase da análise recai sobre a relação entre a mudança social e a construção/desconstrução histórica da identidade profissional dos professores públicos, em um processo que articula flexibilização, autonomia e profissão. De modo que o atual dilema colocado pelas reformas educacionais contemporâneas está no paradoxo entre flexibilização ou autonomia profissional docente, expressando, para além de uma questão meramente econômica ou produtivista, um fenômeno de ordem político-cultural em um contexto de modernização e/ou de mudança social marcadamente neoliberal.

Por um lado, confirma-se a avaliação como estratégia de despolitização, quando se considera, conforme Pierre Bourdieu (1998 apud MARQUes, 2000, 2002), a utopia neoliberal como um projeto científico de conhecimento, convertido em programa político de ação de "destruição metódica da coletividade", "visando a pôr em questão todas as estruturas coletivas capazes de levantar obstáculos à lógica do mercado puro", o que inclui "o desaparecimento progressivo dos universos autônomos de produção cultural", instaurando "o reino absoluto da flexibilidade" (Bourdieu, 1998, p. 7).

Por outro lado, confirma-se a avaliação como estratégia de desprofissionalização, "por constituir uma forma de o governo controlar a produtividade dos docentes das universidades públicas federais 
concedendo um aumento salarial, em forma de gratificação variável vinculada á avaliação do desempenho individual, traduzida na GED” (Rocha, 2005, p. 84).

Nesse sentido, entendo que Vânia Rocha (2005, p. 10) consegue o objetivo de "avançar o debate na área [do ensino superior] e contribuir, criticamente, para a construção de uma universidade pública, democrática, autônoma e de qualidade, no Brasil".

\begin{abstract}
This text is an analysis of 'Research into Policies for Teacher Evaluation in Higher Education', by Vânia Amaral da Rocha. Produced to support my participation as a titular member of the Defense Panel of the above-mentioned Dissertation, the aim of the text was to deal with Vânia Rocha's research process, as a means of contributing both to a personal reflection on my own work as tutor in the Post-Graduate Program at UFU, and as a self-reflection of the author on her research into the field of public policies for Higher Education. So using the works of Isaura Belloni, Heitor de Magalhães and Luzia Sousa as a theoretical basis, the theme, relevance, methodology, references for analysis and results of the above-mentioned research are treated.
\end{abstract}

Key words: educational research; public policy; higher education; evaluation

\title{
NOTAS
}

1. Os autores, neste caso, analisam a proposta da política nacional de educação profissional (PNEP) e do plano nacional de formação (PLANFOR), da Secretaria de Formação e Desenvolvimento Profissional (SEFOR) do Ministério de Trabalho (MTb).

2. A este respeito, é interessante a consideração de que, ao menos nos anos de 1990, o sentido de uma avaliação global é empobrecido pela identificação restritiva entre avaliação institucional, avaliação do ensino superior e avaliação acadêmica ou do trabalho intelectual (BELLONI, 1998 apud Rocha, 2005, p.7475).

3. A propósito, consultar Vânia Rocha (2002).

4. Suposição reforçada pelo sentido predominante dos objetivos (Rocha, 2005, p. 4), do próprio desenvolvimento - do total somente 29 páginas tratam da GED na UFU (Idem, 2005, p. 93-122), bem como das considerações finais (Idem, 2005, p. 123-126), de caráter mais geral e menos afeito ao sentido gestionário e organizacional específico da instituição UFU. 
5. Segundo os autores, uma política pública pode assumir outros papéis, podendo ter, ainda, característica de ser "complementar" ou "reparadora ou compensatória" (p. 33-34).

6. Com base em Bardin, Moscovici e outras referências clássicas, os autores se referem a três etapas: organização de material de trabalho, definição das unidades de registro e definição das categorias.

7. CNAO-GED: Comissão Nacional de Acompanhamento e Orientação da Gratificação de Estímulo à Docência.

\section{REFERÊNCIAS}

BELLONI, I.; MAGALHÃES, H. de; SOUSA, L. C. de. Metodologia de avaliação em políticas públicas. 2. ed. São Paulo: Cortez, 2001. (Coleção Questões de Nossa Época, v. 75).

BOURDIEU, P. A máquina infernal. Folha de S. Paulo, 12 jul. 1998, c. 5, p.7.

MARQUES, M. R. A. Autonomia ou flexibilização: o atual dilema profissional docente. In: SGUISSARDI, V. (Org.) Educação superior-novos e velhos desafios. São Paulo: Xamã, 2000. p. 219-234.

Políticas públicas e práticas escolares nos programas de formação docente. IN. CICILLINI, G. A.; NOGUEIRA, S. V. Educação escolar-política, saberes e práticas pedagógicas. Uberlândia: Edufu, 2002. p. 163-190.

Um fino tecido de muitos fios... mudança social e reforma educacional em Minas Gerais. Piracicaba, 2000. Tese (Doutorado em Educação) - Universidade Metodista de Piracicaba.

OLIVEIRA, E. de; ENS, R. T.; ANDRADE, D. B. S. F.; MUSSIS, C. R. de. Análise de conteúdo e pesquisa na ares da educação. In: Revista diálogo educacional, Curitiba: PUCPR/Champagnat, v. 4, n. 9, mai.-ago. 2003, p. 11-27.

ROCHA, V. A. da. O processo de avaliação de desempenho na percepção do gerente: um estudo introdutório na Universidade Federal de Uberlândia, 2002, 53 p. Monografia de Curso de Especialização da Faculdade de Educação.

Políticas de avaliação docente no ensino superior - a Gratificação de Estímulo à Docência (GED) na Universidade Federal de Uberlândia. Uberlândia, 2005, 225 p. Dissertação (Mestrado em Educação) Universidade Federal de Uberlândia. 
